\title{
Tributo a Florestan Fernandes: reminiscências de um incomum, destemido e fundamental desafio
}

MARLI AURAS*

Universidade Federal de Santa Catarina, Florianópolis- SC, Brasil.

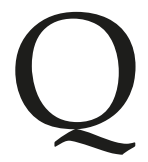

uando fui fazer o doutorado na área da Educação, na PUC/SP, em 1985, logo vários colegas me alertaram para não deixar de fazer o curso que estava sendo ofertado pelo professor Florestan Fernandes, "Análise dos processos revolucionários". Em 1984, por iniciativa de alguns dos pós-gradua ndos, suas aulas foram gravadas (com seu devido consentimento, é claro), em fitas k7, e, depois, diligentemente transcritas e datilografadas. Essa transcrição, por sua vez, ainda sofreu uma cuidadosa revisão, acompanhada da audição das gravações, o que, enfim, acabou por resultar num volumoso conjunto de páginas e páginas datilografadas e, ao mesmo tempo, contendo várias correções e acréscimos feitos a mão, em letra cursiva legível, num criterioso trabalho de equipe, de modo a tornar a leitura do material a mais fiel possível ao que havia sido exposto pelo professor. Todo esse empenho resultou em preciosas 336 páginas, que foram encadernadas em dois volumes espiralados. Esse trabalho artesanal de edição, concluído meses após, possibilitou aos discentes interessados ter seu próprio exemplar fotocopiado da íntegra do curso que havia sido dado pelo professor Florestan, no segundo semestre de 1984. Em 1986, de posse de um desses exemplares, tive também o privilégio de cursar a disciplina oferecida pelo professor Florestan Fernandes.

Ao ser convidada pela professora Leda Scheibe, professora emérita da UFSC e colega de longa data, para escrever este texto, a partir de minha vivência, de minhas próprias memórias como aluna do professor Florestan Fernandes, não tive dúvida de que atender tal desafio implicava localizar meus volumes espiralados. Mas, diante de todo o tempo já decorrido ( 32 anos!) de minhas mudanças de domicílio e de algumas malfadadas intempéries, até mesmo da muito provável ação de traças, seria possível localizá-los ainda em condição de leitura, haja vista inclusive ter-se tratado de uma edição rudimentar, xerocopiada? Pois os encontrei na parte inferior e fechada de uma estante há muito não frequentada, ambos dormitando numa prateleira já arcada pelo peso de tudo que

* Possui mestrado em Educação: História, Política, Sociedade pela Pontifícia Universidade Católica de São Paulo e doutorado em Educação: História, Política, Sociedade pela Pontifícia Universidade Católica de São Paulo. Atualmente é Professora Voluntária da Universidade Federal de Santa Catarina. E-mail: $<$ marliauras@yahoo.com.br>. 
lhe foi superposto, por anos a fio. Uma fina camada da poeira do tempo, esfumaçada, cobria os exemplares, tingindo os meus dedos. Os pretos espirais, plastificados, estavam inteiros, mas parecendo túneis tal a quantidade de pequenas teias e protuberâncias, num cinzento emaranhado, caprichosamente costuradas pelo tempo. As traças, enfim, haviam aberto apenas pequenos sulcos nas beiradas dos volumes, sem maiores danos.

Emocionada, tratei logo de trazer esse material para o presente, à luz do dia, numa transposição carregada de belos e densos significados, ainda bastante vivos em minha memória. Depois de proceder à necessária limpeza dos volumes, abri e comecei a folhear. Então constatei que algumas páginas estavam como que coladas, uma sobre a outra, mas se desprendiam com facilidade, sem praticamente resistência. Para a minha surpresa e satisfação, era possível ler a integralidade do material, ainda que uma ou outra página estivesse meio esmaecida. Enfim, decorridas mais de três décadas, eis-me a ter o privilégio de poder revisitar/reler o curso dado pelo professor Florestan Fernandes em 1984 e que pude fazer regularmente, em 1986, lá na PUC/SP.

Frequentei suas aulas no último curso acadêmico por ele oferecido naquela Universidade, haja vista que, no final de 1986, foi eleito deputado federal pelo PT, indo integrar a Assembleia Nacional Constituinte, com destacada e reconhecida militância em favor dos debaixo. Éramos cerca de trinta doutorandos, das áreas das Ciências Sociais, História, Filosofia, Educação, dispostos numa sala de aula comum. As aulas eram expositivas e o ambiente prezava pelo silêncio e por muita atenção, pois o professor, naquela altura já adoecido, por vezes se exprimia num tom de voz mais baixo, ainda que estivesse invariavelmente atilado, fecundo, instigante. Suas exposições eram extraordinárias, palavra que quer dizer "fora do comum"; estar ali, diante de alguém com tamanho e raro acúmulo de conhecimentos, autor de obras seminais, já era, por si só, uma experiência discente única, irrepetível, imorredoura, até mesmo envaidecedora. Mas uma experiência a nos implicar politicamente, sobretudo pelo conteúdo de suas exposições e convicções, a partir da luta de classes, a nos cobrar lucidez e firmeza de propósitos para com as demandas históricas do polo do trabalho, enfim, a nos desafiar a refletir e a produzir conhecimentos a partir dos debaixo, a ver/ler/sintetizar o mundo a partir dos subalternos, na perspectiva da construção e aprofundamento do processo de desalienação como condição do aparecimento de uma nova forma de ser social, tendo-se presente que o socialismo é um movimento real, capaz de brotar do chão histórico brasileiro como expressão de nossa própria luta, como transformação, uma vez que a revolução social é uma realidade histórica. O professor alertava: “Eu acho que a imaginação de Marx (...) não foi utópica. Ela foi dialética, no sentido mais genuinamente materialista que se possa imaginar"1. "Nós não podemos prescindir da teoria para ver. Se não temos uma teoria revolucionária, não vemos a necessidade da revolução, [sua] congruência intrínseca (...). Por isso Lenin dizia, 'sem teoria revolucionária não há revolução'. Mas, acontece que os fatos são os fatos, e eles não existem para satisfazer uma teoria revolucionária"² "Os revolucionários 
podem fazer muitas coisas, mas não podem criar a revolução. Esse é o problema central. Pensando em termos marxistas, a revolução não é um produto da vontade de um grupo de revolucionários" ${ }^{3}$. "Vocês devem estar lembrados, já mencionei aqui, aquela frase de Lenin, 'as revoluções não se fazem de encomenda'. Elas são parte de um complexo e prolongado processo social" " . "Seria preciso dizer que não se faz sob encomenda e também não se faz num dia, não é? Se ela pudesse ser feita de encomenda, poderia ser uma revolução perfeita: e se ela se fizesse num dia, resolveria todas as questões de uma maneira tão rápida que o que era revolução num dia já seria ordem no dia seguinte. É preciso pensar as revoluções numa escala de tempo longo, prolongado" ${ }^{\prime 2}$.

O desenvolvimento do curso, "Análise dos processos revolucionários", se deu através dos seguintes eixos temáticos: Tema 1 - Luta de classes e revolução. O conceito sociológico de revolução. Tema 2 - Variedades históricas e estruturais de Revolução Burguesa. O que era e o que não poderia ser revolucionário nas situações de classe dominante da burguesia. Tema 3 - Socialismo e luta de classes. "Reforma" e "revolução" nos países capitalistas centrais e periféricos. Tema 4 - Imperialismo e contrarrevolução preventiva em escala mundial. Tema 5 - A Revolução Russa - Um paradigma de revolução proletária (foi a exposição mais abrangente, desdobrada em cinco tópicos, que foram trabalhados em quatro encontros semanais). Tema 6 -A Revolução Cubana. Tema 7 - As perspectivas do socialismo revolucionário no Brasil ${ }^{6}$. Este último tema foi desdobrado em três tópicos: 7.1 - Luta de classes: o difícil crescimento do polo do trabalho. 7.2 - Transformações mais recentes no regime de classes. Desenvolvimento do capitalismo. 7.3 - Na luta de classes, alternativas da presença operária. Revolução contra a ordem e revolução dentro da ordem.

A bibliografia do curso era simplesmente monumental, de largo alcance internacional, mas também nativo, de pensadores clássicos (sobretudo do campo da esquerda, mas não somente) aos autores mais pontuais, que haviam se reportado, por exemplo, como testemunhas sensíveis, a determinados processos paradigmáticos de ruptura da ordem social vigente. Era comum, no desenrolar de suas exposições, o professor lançar mão da contribuição de vários outros autores, citando algumas falas e referenciando a obra. "Esse livro tem na biblioteca, recomendo aos senhores que o leiam", essa era uma observação que fazia com frequência. Ele era sempre muito elegante no trato com os autores pautados, mesmo aqueles do campo conservador de substancial contribuição ao avançar do conhecimento. Aliás, sua relação com os alunos era também atravessada pelo respeito e fidalguia. "Há pouco o senhor havia feito uma pergunta", "agora, vou abrir para as perguntas dos senhores", "a senhora quer saber"; senhor, senhora era o trato comumente dispensado a todos nós, seus alunos. Por mais disparatada que pudesse ser uma pergunta, o professor Florestan Fernandes mantinha a serenidade e conseguia transformar aquela intervenção em algo que fizesse sentido, que tivesse a ver, ainda que tangencialmente, com o fluxo da temática em exposição. Longe do perfil do professor humilhar 
um aluno! Afinal, como profundo conhecedor dos dilemas e mazelas da educação brasileira, reconhecia inclusive que "todos temos direito a sermos superficiais" (sem com isso, no entanto, tipificar a fala de quem quer que seja na sala de aula), daí sua enorme instigação para com o aprofundamento das leituras e das pesquisas, enfim, para com a realização de estudos em patamares mais rigorosos, mais avançados e, acima de tudo, socialmente referenciados, na direção do polo do trabalho. Ele próprio, um professor com tamanha sabedoria e indiscutível firmeza de propósitos, com invulgar trajetória de vida, já significava, por si só, caminho, descortino, exemplaridade. Convite ao rigor intelectual, aliado ao comprometimento histórico-social.

Era tamanho o seu compromisso e sua sensibilidade para com a causa socialista que não escondia dos alunos haver chegado ao choro na leitura de certas obras. Os volumes espiralados do curso tratam de dois desses momentos, o primeiro, tem a ver com a Revolução Russa, ao citar o livro El año uno de la Revolución Russa, de Victor Serge, que o professor considerava "um autor muito lúcido na descrição desse processo": "quando tinha que optar entre a ditadura dos generais brancos e a do seu próprio partido, [a classe operária] não desobedecia (...); acudiam todos os seus homens válidos, a empunhar o fuzil, e se alinhavam em silêncio sob as janelas do local em que estavam instalados os comitês do partido". Inscrever-se para essa luta, sublinhava o professor, significava aceitar que, muito provavelmente, o camarada seria morto, que iria dar a vida pela revolução. "A primeira vez que li esse trecho, eu chorei. Vocês têm que imaginar esses operários, que vão à extrema consequência do sacrifício, não é?"7 .O segundo momento, tem a ver com a Revolução Cubana, mais precisamente com a instalação dos guerrilheiros nas montanhas da Sierra Maestra, na segunda metade dos anos 1950. Na fala do próprio professor: "É verdadeiramente emocionante ler o pequeno ensaio de Che Guevara, é a coisa mais bela que alguém escreveu na América Latina! Um ensaio que trata da trajetória da guerrilha, dá um enfoque político e apanha o processo revolucionário de ponta a ponta. Além de Che Guevara ser uma pessoa que viveu os acontecimentos, é um homem de penetração psicológica humana, um homem sensível, um homem amoroso, um revolucionário firme, ardoroso, um homem de talento criativo. (...) [Os guerrilheiros em Sierra Maestra] vão trabalhar (...), não vão fazer o que os camponeses faziam (porque os camponeses trocavam alimentos com eles), mas vão trabalhar em outras coisas, adquirem calos pelas outras coisas que vão fazer, vão fundar escolas, vão alfabetizar os camponeses, vão criar a primeira forma de assistência hospitalar que eles conheceram na vida, com eles organizam sortidas às fazendas, principalmente fazendas governamentais, para sumir gado, para terem mantimentos. Eles vão repartir esses mantimentos com os camponeses que - pela primeira em que eu li essa frase de Che, eu chorei, quando ele descreve as emoções dos camponeses -, pela primeira vez na vida, comeram carne de boi. É linda a descrição, é emocionante!"8. 
Diante desse exemplo, o professor chamava a atenção para o fato de que lá em Sierra Maestra os guerrilheiros haviam tratado de criar, naquelas difíceis circunstâncias, um protoestado, já na perspectiva socialista. Lembro que o professor, em suas aulas, procurava acentuar a importância, para todos os defensores do campo socialista, de se buscar/ ousar viver segundo princípios socialistas, de modo a se estabelecer contrapontos com o polo burguês dominante. Isso vai ao encontro do entendimento de que o socialismo não é uma invenção puramente teórica, dada a priori, fruto de um cérebro genial, como o de Marx, mas é um movimento real, concreto, o que implica compreender o jogo das forças histórico-sociais vigentes, no processo de construção dessa nova forma de ser social. Nesse processo, podemos entender a importância histórica da contribuição da luta pela disseminação e melhoria da qualidade da educação pública e gratuita, em todos os níveis de escolaridade.

Na releitura dos volumes espiralados, fiz alguns destaques. Dentre eles, tomo a liberdade de apresentar alguns, como expressões exemplares do pensamento do professor Florestan Fernandes, em posição ofensiva, na contramão do conhecimento vigente, uma vez que considera o princípio de que "o trabalho intelectual também pode assumir as feições de uma guerrilha..." . "A ideologia da classe dominante nunca foi tão maciça, nunca foi tão imperialista como sucede hoje nos Estados Unidos, a tal ponto que vocês têm dois partidos que aparentemente são antagônicos, e que na realidade possuem diferenças de matiz, não diferenças de natureza. Não se pode dizer que um é liberal e o outro seja reacionário. Ambos são ultraconservadores, embora um tenha uma 'crispação' liberal e o outro um núcleo central reacionário. Na verdade, a realidade é tão chocante que uma grande massa de eleitores não vai votar, porque não é decisivo escolher um ou outro, as nuances desapareceram. Isso é uma realidade que tem uma base estrutural e que está vinculada à própria organização do trabalho e às técnicas de universalização do conformismo. Todas as instituições chave trabalham aí: a escola, a igreja, a grande imprensa, a televisão. Todas elas bombardeiam o indivíduo com os símbolos da ordem, da identificação com a ordem e da defesa da ordem, de modo que o radicalismo quase sempre tem frinchas muito estreitas. Ele nem pode eclodir como luta de classe contra classe, isso já seria concebido como uma ruptura muito violenta para ser tolerada. Ele tem que emergir como uma divergência de caráter setorial ou local. Divergência, por exemplo, erguida por homossexuais, em termos de raça, em termos de sexo e por aí afora. As grandes bandeiras que ligavam classes, luta de classes, revolução social, não desapareceram, mas estão guardadas nos porões da sociedade" ${ }^{\prime 10}$.

Ainda no interior da temática do imperialismo, sobretudo estadunidense, e da construção da contrarrevolução preventiva em escala mundial, destaco: "Quais são as fronteiras dos Estados Unidos? Onde elas começam e onde terminam? Elas podem começar de um ponto geográfico central dos Estados Unidos, mas vão à América Latina, à Ásia, já estão na Coréia do Sul, estão nos países limítrofes ao Leste da Europa, estão em 
todo lugar onde existem riquezas essenciais para o funcionamento da máquina produtiva dos Estados Unidos e para a sua sobrevivência e crescimento. A mesma coisa vocês podem pensar das outras nações. Quer dizer, as fronteiras são fronteiras que não correspondem aos territórios controlados por essas nações. Aquela ideia de que uma nação se define por ter limites, já era!; as fronteiras do Estado Nacional, isso é ficção!" ${ }^{11}$. E correlato a isso, ao expor o processo da Revolução Cubana: "(...) a burguesia não tem patriotismo, tem é capital, e quando o patriotismo serve para defender o capital, muito bem, quando não serve, o patriotismo é posto na lata original do capital"12.

Vejamos alguns destaques que têm a ver diretamente conosco, com a temática das perspectivas do socialismo revolucionário no Brasil. “Quanto ao primeiro ponto [o polo do trabalho], nunca é demais que vocês pensem o quanto nós estamos próximos do regime escravista. Nós, quase sempre, por causa de nossa urbanidade, de nossa euforia tropical, sempre nos lembramos que somos pessoas que têm TV, geladeira. Nós nos projetamos muito na realidade moderna do mundo e nos esquecemos do preço que pagamos por isso e como é artificial essa projeção. Há quantos anos nós estamos da abolição da escravatura? 1888, quer dizer, não dá um século, nós não temos um século de evolução do regime do trabalhador livre. Quer dizer, isso nos permite visualizar o nosso presente em termos de uma situação na qual escravo e trabalhador é um... o que? A mesma coisa. Quem era o trabalhador? Era o escravo. E visualize uma outra situação na qual o escravo é substituído pelo trabalhador (...) o trabalho livre, literalmente, o que é o trabalho livre? É o substituto e o equivalente do trabalho escravo. E isso é tão recente, fim do século XIX"13.

Com relação à ruptura institucional brasileira ocorrida nos anos 1960: “(...) se 1964 volta a dizer que a greve e os sindicatos são casos de polícia, isso mostra que, de fato, não são os trabalhadores que são passivos, é a classe dominante que não é capaz de renovar seu estoque de soluções para os problemas sociais. Ela procura sempre usar a repressão e a opressão como mecanismo de controle das tensões, ao invés de fazer o que fizeram outras burguesias, em outras condições, que absorveram as pressões, acelerando as mudanças. O conservador, no Brasil, procura impedir a mudanças, assumir o controle da mudança, enquanto que o conservador na Inglaterra prefere muito mais regulamentar as condições de conflito, de modo que a pressão de baixo acaba perdendo a eficácia e as reivindicações são absorvidas, incorporadas à ordem, e a ordem se fortalece nesse processo de se defender. Aqui, no processo de se defender, a ordem não se fortalece, ao contrário, ela fica tão fraca que os de cima são obrigados a recorrer constantemente ao golpe de Estado, à repressão policial, à repressão militar, para manterem os debaixo sob controle"14. Ainda com relação ao golpe de 1964: “Agora, em 1964, esse movimento (...) vai se dar sob a filosofia do desenvolvimento com segurança. Essa norma, desenvolvimento com segurança, foi criada na superpotência capitalista, veio a partir dos Estados Unidos. Desenvolvimento com segurança quer dizer não desenvolvimento com segurança nacional, mas desenvolvimento com segurança para o capital, entendendo-se capital 
privado nacional e estrangeiro. Quer dizer, o desenvolvimento com segurança do capital, que não quer ser ameaçado por qualquer instabilidade política, que não quer se ver diante da iminência de, de repente, ser nacionalizado, sofrer os percalços de uma turbulência incontrolável. Então, o desenvolvimento com segurança significava (...) acelerar o desenvolvimento econômico. O desenvolvimento econômico era prioridade número um. Não existiam os problemas de integração da sociedade nacional, desigualdade de regiões, desigualdade de renda, pobreza, miséria, desemprego. O único problema que deveria ser equacionado era o da aceleração do processo de acumulação capitalista, que devia ser acelerado até os seus limites mais extremos, à custa de tudo"15. "É possível, numa sociedade capitalista, criar as condições de desenvolver o capital e ao mesmo tempo impedir o desenvolvimento do trabalho? É claro que não é. Seria o melhor dos mundos para qualquer burguesia ter essas duas coisas, de um lado, o desenvolvimento do capital de uma maneira acelerada, e de outro, manter o trabalho como uma entidade passiva, sob coação política, naturalmente, sob repressão e opressão"16.

No bojo do processo do desenvolvimento do capitalismo, aqui no Brasil, "vai surgir uma classe média moderna, que está vinculada ao que se chama hoje de uma tecnocracia. É um setor que vai gerir, vai se encarregar da gestão, tanto no plano militar quanto no plano estatal e quanto no plano da empresa privada, em diferentes níveis. Esse setor da classe média (...) vai ter um nível de vida externa quase que parecido com a grande burguesia, enquanto que em termos propriamente de mentalidade, de comportamento, vai se identificar com os interesses capitalistas, de uma forma permanente"17. "Quando o conservador já não pode deter o processo, ele entra no processo tentando ver como interromper ou tornar seus ritmos mais baixos, de tal modo que uma coisa que poderia ser feita rapidamente, em dois, três anos, acabe exigindo quinze, vinte anos para ser conseguida. Vocês viram que, de 1945 a 1964, o que a nossa burguesia detém não era uma revolução, era uma consolidação de uma democracia de participação ampliada. (...) isso foi chamado de 'república sindicalista', mas realmente o que nossa burguesia renegou foi uma democracia de participação ampliada. O que ela enterrou foi isso"18.

O professor Florestan Fernandes chamava sempre a atenção para o "caráter violento e altamente repressivo de nossa burguesia, que não abriu espaço para que o processo [de autonomia operária] aparecesse"19 "Esse é o panorama: a sociedade brasileira parece um caldeirão!"20. "(...) a luta de classes vai se tornar uma realidade mais abrangente, multifacetária, polivalente. E é claro que se, num primeiro momento, é fácil recorrer à ditadura, num outro momento isso pode ser muito perigoso, porque, vamos supor que ainda agora os militares possam restabelecer dado grau de controle coercitivo, isso não significa que poderão fazê-lo indefinidamente. Nós estamos nos aproximando de um ponto em que vai ser mais arriscado recorrer ao arbítrio para tentar garantir a estabilidade política da ordem. (...) ao invés da interferência militar provocar uma reação de obediência, ela pode provocar a exercer a reação de desobediência civil (...). Então nós chegamos ao problema 
central (...), numa sociedade na qual a burguesia é incapaz de estabelecer ou garantir um regime de democracia burguesa, o que vai acontecer? A democracia vai ser um parto mais complicado"21. "(...) do jeito que nós estamos indo se agravou de tal maneira o desenvolvimento desigual da sociedade brasileira que isso ameaça o equilíbrio de toda a ordem. Então, a revolução nacional tem de ser retomada (...), os aprendizes de feiticeiros soltaram todos os demônios e agora não podem enfiar os demônios dentro do livro. Eles saíram de lá. Agora é preciso enfrentar as pressões, que vêm de todo lado"22.

Buscar entender o mundo, a partir da perspectiva do trabalho, é um desafio a evidenciar que o conteúdo ao qual se chega é, necessariamente, outro, com análises e sínteses bem distintas das vigentes. "A partir do momento em que a classe trabalhadora passa a substituir ideias e valores, que são da ordem existente, por ideias e valores que são contra a ordem existente, aí as classes trabalhadoras passam a ser uma ameaça. Esse processo se delineia claramente, ele está ocorrendo, (...), não é alguma coisa que eu esteja inventando ou que algum professor, historiador ou sociólogo precisa inventar. O trabalhador já sente que ele não pode explicar a realidade da sociedade brasileira pelas categorias que recebe dos economistas ou dos historiadores ou dos sociólogos que são escravos da ordem. Ele precisa explicar por outras categorias. Eu fiz conferências em vários grupos operários, em vários lugares do Brasil. Eu senti essa necessidade. $O$ pessoal quer uma explicação do tipo da que eu dei aqui. Levantar esse quadro e mostrar os processos que se tornam possíveis a partir da própria transformação da sociedade. Eles querem se localizar historicamente" 23 . "Outro dia, tive uma conversa com um médico, de extrema competência técnica, (...) pertencente ao corpo docente do Hospital das Clínicas, com títulos, etc. Agora, o homem é de um reacionarismo assustador! É tão obcecado pela situação brasileira que, do ponto de vista dele, o Brasil devia praticar seleção negativa com relação a toda essa parte da população que foi atingida pela fome e pela degradação que a fome produz no ser humano. Então, ele diz, 'dessa gente, só se aproveitam as crianças; separar as crianças deles e deixá-los à sua própria sorte, que morram onde estiverem, em qualquer lugar do Brasil'. Quando uma pessoa esclarecida pensa isso, vocês vêm que realmente na balança está fascismo de um lado e socialismo revolucionário de outro, quer dizer, o capitalismo falhou, não oferece alternativas. Elepoderia ter oferecido, mas não chegou a oferecer porque é um capitalismo de periferia, um capitalismo que passa pelos egoísmos de superpotências, da burguesia local e dos privilégios que têm prioridades sobre a natureza humana, sobre a condição humana"24.

Enfim, a meu ver, as observações e excertos aqui postos dão bem a medida do quão substancioso, instigante e desafiador foi aquele curso. No decorrer dele, em algum momento da aula, era comum o professor afirmar, a despeito de toda a grande síntese que acabara de fazer:: "aqui haveria muita coisa ainda a salientar e acho que o tempo não nos deixa. Infelizmente, nós não podemos explorar todo o esquema expositivo", fato que, por si só, tornava evidente a vastidão e a profundidade do seu conhecimento, 
na perspectiva da evolução do trabalho como categoria histórica, que foi a questão norteadora da exposição dos sete temas elencados.

Hoje, mais do que nunca, a pertinência e a fecundidade do pensamento e da militância do professor Florestan Fernandes está a nos apontar a direção por onde trilharmos, como profissionais e militantes: darmos prioridade à solução dos problemas humanos, o que é claramente incompatível com a prioridade ao lucro. Isso implica, dentre outras frentes de luta, defendermos a escola pública e gratuita, em todos os níveis.

Recebido em 15/12/18 e Aprovado em 17/015/18

\section{Notas}

1 Exposição do tema 1, p. 35.

2 Exposição do tema 5, p. 44.

3 Exposição do tema 5, p. 02.

4 Exposição do tema 5, p. 01.

5 Exposição do tema 5, p. 54-55.

6 Um oitavo tema ("A situação atual da América Latina - Revoluções interrompidas") não foi desenvolvido pelo professor em sala de aula, mas foi trabalhado pelos alunos, sob forma de seminários. O que o professor Florestan Fernandes pensa sobre o assunto está posto em seu livro "Poder e contrapoder na América Latina", editado pela Zahar, em 1981, especialmente no último capítulo.

7 Exposição do tema 5, p. 53. Em 2007, a Boitempo lançou em português esse livro de Victor Serge, O ano I da Revolução Russa.

8 Exposição do tema 6, p. 17.

9 Florestan Fernandes, Da guerrilha ao socialismo: a revolução cubana, T. A. Queiroz Editor, São Paulo, 1979, p. 02 .

10 Exposição do tema 4, p. 19-20.

11 Exposição do tema 4, p. 26.

12 Exposição do tema 6, p. 31-32.

13 Exposição do tema 7, p. 02.

14 Exposição do tema 7, p. 17-18.

15 Exposição do tema 7, p. 18-19.

16 Exposição do tema 7, p. 19.

17 Exposição do tema 7, p. 20.

18 Exposição do tema 7, p. 29. 
19 Exposição do tema 7, p. 23.

20 Exposição de tema 7, p. 26.

21 Exposição do tema 7, p. 28.

22 Exposição do tema 7, p. 31-32.

23 Exposição do tema 7, p. 33.

24 Exposição do tema 7, p. 34. 